\title{
"A REFORMA DE 1890" - CONTINUIDADES E MUDANÇAS NA ESCOLA NACIONAL DE BELAS ARTES (1890-1900)
}

\author{
Camila Dazzi \\ Professora do Ensino Superior do CEFET-RJ/UnED Nova Friburgo. \\ Aluna de Doutorado do Departamento de Pós-graduação em Artes Visuais \\ - EBA/UFRJ
}

\section{Limites historiográficos}

Apesar da importância da Academia Imperial/Escola Nacional de Belas Artes (AIBA/ENBA) nunca ter sido negada no cenário artístico nacional, a sua historiografia apresenta várias limitações. A primeira delas diz respeito à concentração em alguns de seus períodos históricos, fato facilmente verificável em uma desigual e pouco ampla bibliografia, onde prevalecem os estudos sobre momentos considerados privilegiados, como a implantação da Academia pelos mestres franceses entre 1816 e 1826 ${ }^{1}$, as transformações ocorridas em meados do século XIX, que se iniciaram na administração de Félix Émile Taunay e se complementaram no mandato de Manuel de Araújo Porto Alegre ${ }^{2}$ e os anos de 1880, marcados pelas reivindicações radicais na estrutura da Academia, e por acontecimentos artísticos, como a formação do chamado Grupo Grimm.

O que verificamos, portanto, é que apesar de sua significativa importância, o papel desempenhado pela Escola Nacional de Belas Artes, assim como o de seus professores, no período inicial da República, não mereceu, ainda, a revisão que lhe é devida. Não é incomum, em livros de História do Brasil 3 , encontrarmos listadas dentre as primeiras medidas do Governo Provisório, formado na noite de 15 de novembro: a "grande naturalização, que ofereceu cidadania brasileira a todos os estrangeiros

\footnotetext{
CONDURU, Roberto et alli. Missão Francesa no Brasil. Rio de Janeiro; Sextante, 2004.

2 O período é amplamente estudado por Alfredo Galvão, ainda sob um través modernista, e recentemente revisto por Cybele Vidal Neto Fernandes na sua tese Os caminhos da arte: ensino artístico na Academia Imperial de Belas Artes, e por Sonia Gomes Pereira, em inúmeros artigos, dentre os quais é valido mencionar "Academia Imperial de Belas Artes no Rio de Janeiro: revisão historiográfica e estado da questão".

3 Nos referimos aqui sobretudo a livros não pertencentes a área de História da Arte, mas que, no entanto, atribuem importância significativa aos eventos mencionados. Só para mencionarmos um: KOSHIBA, Luiz. História do Brasil. Atual Editora. p. 144. SCHWARCZ, Lilia. As Barbas do Imperador - Um monarca nos trópicos. Rio de Janeiro: Companhia da Letras, 1999
} 
residentes; a separação do Estado da Igreja (padroado); a instituição do casamento e o "encilhamento". Mas não se menciona o fato de que, apenas 15 dias após a formação do Governo Provisório, ou seja, em 30 de novembro, este mesmo governo nomeava uma comissão, formada por Rodolpho Bernardelli e Rodolpho Amoedo, cujo propósito era a reforma dos estatutos da Academia4. Diante deste fato fica difícil negar a importância que Escola, enquanto principal instituição de ensino artístico do país, possuía para o recém inaugurado Governo Republicano.

Como explicar este desinteresse? Tal limitação historiográfica pode ser elucidada, principalmente, graças ao notório anti-academicismo que vigorou até bem pouco tempo na cena artística brasileira ${ }^{5}$, e que propagou a idéia recorrente sobre o papel da Escola Nacional de Belas Artes de passividade generalizada em relação à modernidade. A Escola, principalmente após a "Reforma de 1890", aparece sempre como o lugar do conformismo, homogeneamente resistente às mudanças.

Tal imagem começou a ser forjada já nas décadas iniciais do século XX pela pena dos então críticos da instituição - podemos citar aqui dois nomes de destaque do meio artístico carioca, como o do pintor Modesto Brocos, que em seu livro A questão do ensino de Bellas Artes seguido da critica sobre a direção Bernardelli e justificação do autor, colocava que o ensino ministrado na instituição "continuou a ser em seu fundo, ensino e disciplinas, pouco mais ou menos do que era no tempo do Império ou, para falar com franqueza, a mesma cousa", ou como o do crítico de arte Gonzaga Duque, que no seu famoso livro Contemporâneos, afirmava que a reforma de 1890 não teria passado de uma mera "questão de rótulo"7. Tal imagem da Escola, que perdurou durante quase todo o século passado, tornou-se uma das peças centrais daquilo que poderíamos chamar "mito fundador" do modernismo brasileiro, que nada mais fez que incorporar a "idéia força do ideário modernista francês, qual seja, a da exigência de se

4 Acervo Arquivístico do Museu Dom João VI/EBA/UFRJ. Notação: 3518. Ofcicio da Secretaria Nacional do Interior, datado de 30 de Novembro de 1889.

5 Sobre o papel da Escola Nacional de Belas Artes, ver: VALLE, Arthur Gomes. A pintura da Escola Nacional de Belas Artes na $1^{a}$ República (1890-1930): da formação do pintor aos seus modos estilísticos. Rio de Janeiro:EBA/UFRJ, 2007. (tese de doutorado)

- BROCOS, Modesto. A questão do ensino de Bellas Artes seguido da critica sobre a direção Bernardelli e justificação do autor.. Rio de Janeiro: s/ed, 1915, pp.44-45.

7 DUQUE ESTRADA, Luis G. Contemporâneos. Rio de Janeiro: Benedito de Souza, 1929. 
formular como uma revolta contra as instituições artísticas, contra os mandarins dos Salons".

É somente nos últimos 20 anos, com o pós-modernismo e a sua revisão crítica do modernismo, que está sendo possível não somente uma revisão historiográfica sobre assuntos e conceitos antes já tratados, como também à tomada de interesse por períodos ainda obscuros da história da Escola. Neste processo, algumas das noções impostas pelo modernismo estão sendo reavaliadas, como a noção de ruptura total entre acadêmicos e "modernos". Nesse sentido, podemos lembrar aqui brevemente de estudiosos como Sonia Gomes Pereira, Luís Marques e Carlos Zílio. Este último, por exemplo, demonstra como preocupações centrais do ideário modernista especialmente as idéias de "progresso (atualização) e de identidade nacional (nacionalismo)" já se encontravam presentes nas discussões estéticas acadêmicas ${ }^{9}$. De maneira análoga, a produção de dissertações e teses universitárias tem mostrado um interesse sempre renovado pelos pintores acadêmicos do período, como por exemplo a tese de Ana Maria Tavares Cavalcanti que aborda a dinâmica dos prêmios de viagem na AIBA.

Mas apesar das recentes reconsiderações sobre a arte oitocentista no Brasil, podemos notar ainda alguns "ranços" do ideário modernista, que persistem na invariável idéia de que a "Reforma em 1890", além de não contemplar as reivindicações da década anterior, não representou uma ruptura radical com o passado da instituição, não revelando grandes mudanças das concepções formais e pedagógicas da velha Academia.

Basta aqui citarmos o um artigo publicado em 1991, no Suplemento Cultural do jornal O Estado de São Paulo. Segundo este, a modernidade demonstrada por Rodolpho Amoedo, na EGBA de 1884, com o quadro Estudo de Mulher, possuidor de "um realismo distante da idealização de seus antigos mestres locais", teria se perdido sobretudo após o pintor tomar posse como vice-diretor da ENBA, em 1891:

Desde sua posse como vice-diretor da Escola Nacional, em 1890, o artista soube absorver rapidamente os valores morais, puritanos, que pautavam a atuação da antiga Academia. Seu papel ali depois da reforma republicana não foi o de renovador do ensino e da mentalidade existentes naquela instituição

8 MARQUES, Luiz (org.). 30 Mestres da Pintura no Brasil. São Paulo: MASP / Rio de Janeiro: MNBA, 2001 (Catálogo de exposição), pp.21-23.

9 ZILIO, Carlos. "A modernidade efêmera: anos 80 na academia". In: Anais do Seminário EBA 180 (180 anos da Escola de Belas Artes). Rio de Janeiro: Programa de pós-graduação da EBA/UFRJ, 1997. p. 237-242. 
antes da proclamação da República. Pelo contrário: uma vez atuando no território maior da arte oficial brasileira, quer como professor/artista, quer como administrador, Amoedo encarnou os antigos valores daquela instituição, esquecendo-se rapidamente de ter sido um dia vítima deles...

Diante deste quadro, acreditamos que uma revisão historiográfica do período inicial da ENBA se faz absolutamente necessária, a fim de aprofundarmos nosso conhecimento sobre este período de nossa arte marcado por importantes transformações, caracterizado por uma grande vitalidade, e instaurador de um progressivo alargamento dos horizontes estéticos e das estruturas do sistema institucional da arte no Brasil.

\section{As inovações e continuidades na ENBA a partir da Reforma de 1890}

Os anos finais da AIBA foram conturbados. Não é desconhecido, por aqueles que estudam a arte brasileira do século XIX e início do XX, o fato de que durante toda a década de 1880 a AIBA foi alvo de críticas por parte não somente dos críticos de arte, mas também de alguns de seus professores e alunos. A instituição se encontrava, de fato, enfraquecida, assim como estava o regime monárquico ao qual estava profundamente vinculada. A contenção de apoio financeiro à Academia se refletiu, sobretudo, na diminuição dos prêmios de viagem ao estrangeiro, assim como das Exposições Gerais, que costumavam acorrer anualmente. A última, durante o período monárquico, fora a importante exposição de 1884, precedida daquela não menos significativa de 1879 .

Diante deste quadro, multiplicavam-se as críticas que exigiam uma reforma urgente da estrutura e dos métodos de ensino da AIBA, cuja situação precária - agravada pela ausência de parte do corpo docente, em gozo de licença na Europa -, vinha se somar sua ligação com o regime imperial.

Com o advento da República, em novembro de 1889, essa ansiada reforma viria a se tornar uma realidade. Em um primeiro momento, porém, não houve um consenso a respeito de como ela deveria ocorrer, inclusive no interior na própria Academia. Ainda em 1889, uma comissão composta por Rodolfo Bernardelli, Rodolpho Amoedo e Gomes Moreira Maia, este último então diretor da instituição, foi incumbida pelo recém formado Governo Provisório, de elaborar o projeto de reforma da Academia.

No entanto, é fácil verificar, a partir da leitura das Atas da Congregação, que houve a elaboração, na realidade, não de um, mas de três distintos projetos que visavam a reforma. Segundo consta na Ata de 7 de 
abril de 1890: "[um] que veio remetido da Secretaria do Interior, sem nenhuma assinatura; [outro] que apareceu publicado pelas colunas da Gazeta de Notícias, no dia 12 de março e assinado pelos profs. Rodolpho Bernardelli e Rodolpho Amoedo; e o que , na qualidade de membro da comissão, o Sr. Diretor apresenta, em separado". Diante deste quadro, é eleita uma comissão composta por antigos professores da Academia, José Maria de Medeiros, Maximiniano Maffra e Victor Meirelles, cuja função era julgar os três projetos. Para não nos estendermos muito, basta mencionar que o projeto Amoedo-Bernardelli foi bastante criticado pelos membros desta comissão, o que veio a ocasionar o afastamento, ainda no mês de maio, tanto de Amoedo como de Rodolpho Bernardelli da Academia ${ }^{10}$.

A demora por parte dos membros da Academia em definir um projeto, assim como a lentidão do Governo em tomar uma medida mais efetiva sobre a reforma, levou os artistas e críticos de arte, ao longo do ano de 1890, a protestarem contra o ensino artístico ultrapassado da Academia, e a requererem, por parte do governo, uma solução. Só para citarmos, em 26 de julho de 1890, a Gazeta de Noticias, publicava um pedido de subvenção do público, por artistas e professores da Academia das Belas Artes, para que fossem dados cursos públicos e gratuitos enquanto não eram tomadas providências quanto a Academia. Ainda em julho, era noticiado, no Jornal do Commercio, que uma comissão composta por diversos artistas, havia entregado ao governo um documento de supressão da Academia das Belas Artes, uma vez que nenhuma medida sobre a reforma era tomada, e o anuncio da organização de cursos públicos e gratuitos. Em agosto de 1890, nada havia ainda sido decido, e a

Gazetade Noticias elogiava o Atelier Livre de Belas Artes, e reforçava a necessidade de solução sobre a reforma da Academia pelo general Benjamin Constant.

Não podemos deixar de mencionar aqui a sempre citada querela entre Positivistas e Modernos. Cabe chamar a atenção para o fato de que os Positivistas, encabeçados pelas figuras de Montenegro, Décio Villares e Aurélio de Figueiredo, nunca propuseram uma reforma da Academia; o projeto por eles elaborado, e encaminhado ao Governo em janeiro de 1890,

10 Em 04/05/1890 o Jornal do Commercio noticia o pedido de demissão do professor de paisagem Rodolpho Amoedo - Folhetim do Jornal do Commercio (coluna), n. 124, ano 68. Na Acta da Congregação consta que Rodolpho Bernardelli abandonou exercício de todas as suas funções no dia 6 de maio de 1890. Acervo arquivístico do Museu D.João VI/EBA/UFRJ. Acta da Congregação de 6 de outubro de 1890 . 
era muito mais abrangente, uma vez que visava a reforma do ensino das bellas artes no país, inclusive com a extinção da Academia ${ }^{11}$. Tal idéia apesar de, sem sombra de dúvidas, encontrar alguns adeptos, e entre eles o crítico de arte Gonzaga Duque, nunca foi bem quista por grande parte dos artistas e críticos de arte, e muito menos, como sabemos, pelo Governo Republicano, que em 8 de novembro de 1890, com o Decreto n 983, aprova os estatutos para a Escola Nacional das Bellas-Artes - baseados estes no projeto Bernardelli-Amoedo, vindo a nomear, ainda em novembro, Rodolpho Bernardelli como primeiro diretor da academia no período republicano .

Como já dito anteriormente, a implementação da Reforma de 1890 sempre foi muito criticada pala nossa historiografia, pesando sobre ela a acusação de não ter contemplado as reivindicações da década anterior, não representando uma ruptura radical com o passado da instituição. Acreditamos que em relação á esse tópico o primeiro questionamento que devemos nos fazemos é o seguinte: desejavam os formuladores do projeto de reforma (e os demais artistas envolvidos) uma ruptura radical com sistema de ensino da Academia? E será que de fato não ocorreram mudanças significativas no sistema de ensino da Escola Nacional?

Nas pesquisas por nos realizadas até o presente momento, encontramos documentos que nos permitiram averiguar que se "a reforma em 1890 não representou uma ruptura radical com o passado da instituição", é por que, de resto, não era esta a ambição de seus articulistas. Os então chamados "os novos", encabeçados pelos Bernardelli e Rodolpho Amoedo, se opondo ao projeto de pôr fim à Academia, formulado pelos Positivistas $^{12}$, propunham em seu projeto ${ }^{13}$ uma escola de arte atual, em sintonia com as inovações do seu tempo, cuja modernidade, no entanto, não significava rompimento com a tradição, como nos faz saber o crítico de arte Pardal Mallet, convicto defensor dos "novos", em um de seus muitos artigos publicados em no decorrer de 1890:

11 O "Projeto Montenegro" se encontra disponível no site www.dezenovevinte.net .

12 As propostas dos positivistas foram reunidas em um projeto de reforma - o "Projeto Montenegro" redigido pelos pintores Montenegro Cordeiro, Décio Villares e Aurélio de Figueiredo. O projeto foi encaminhado ao Governo em 30 de janeiro de 1890 (segundo nota publicada na gazeta de Noticias, em 24 de junho de 1890).

13 O projeto Bernardelli-Amoedo, datado de 25 de janeiro de 1890, foi publicado na integra em 12 de março de 1890, na Gazeta de Notícias. Título do Escola Especial de Bellas Artes Volume/Suplemento:n. 71, ano XVI. Partes do documento se encontram disponíveis no site: www.dezenovevinte.net . 
Só na Europa existe arte velha e sedimentada; existem escolas diferenciadas no seu processualismo, guerreando-se, rivalizando-se. Aqui existe por fazer. A revolta [contra as academias] na Europa consiste em destruir, a revolta aqui no Brasil consiste em construir. (...) Uma vez colocada em andamento a reforma [da nossa academia] tão urgentemente declamada, entregue a academia à gente nova que tem talento e que tem mocidade, é preciso coloca-la bem, em lugar em que se possa fazer esse trabalho moderno, que não é desprestigio dos velhos mestres; mas que é a continuação do trabalho venerado dos antigos ${ }^{14}$.

Portanto, a sobrevivência de traços fundamentais que caracterizavam já a Academia Imperial, estavam em pleno acordo com o que foi proposto na reforma de 1890. Talvez o mais importante desses traços mantidos tenha sido o modelo tradicional de ensino artístico subvencionado pelo Estado, imprescindível a ENBA enquanto instituição e consolidado na sua estreita ligação com governo republicano recéminstaurado. Isso iria implicar na manutenção de funções já desempenhadas pela antiga AIBA, especialmente daquelas relacionadas à construção de uma identidade e de um imaginário coletivo para o país ${ }^{15}$.

Mas para além das continuidades entre AIBA/ENBA, ocorreram mudanças significativas no que diz respeito a melhoras consideráveis na estrutura da própria instituição. Uma destas melhorias é a revitalização da Pinacoteca da Escola Nacional de Belas Artes, com obras de uma geração mais nova e a par das novidades artísticas ocorridas na Europa. Tal inovação, que vinha sendo pedida desde os tempos da AIBA, se fazia sentir ainda forte no tom das críticas que saiam na imprensa carioca. E, ao menos neste ponto, podemos dizer que alguma reivindicação das décadas anteriores foi satisfeita. A partir da nomeação de Rodolpho como diretor, em novembro 1890, até 1892 foram adquiridas obras de vários artistas, como a tela "Um Louco", do italiano Antonio Mancini; "Derrubada" e "Muito tarde", de Weingarter; "Os Bandeirantes", "Messalina" e, de Henrique Bernardelli; "Balla vista de Nápoles" e "Caminho do Vesúvio",

\footnotetext{
${ }^{14}$ Gazeta de Notícias, dia 07 de julho de 1890.Título:Academia de Bellas Artes II. Autor: Pardal Mallet.

${ }^{15} \mathrm{Um}$ estudo a respeito dos símbolos criados pelos artistas influenciados pelas diversas ideologias que disputavam a primazia no períodos de implantação da República no Brasil pode ser encontrado em CARVALHO, José Murilo de. A Formação das almas: o imaginário da República no Brasil. São Paulo: Companhia das Letras, 1990.
} 
de Parlagreco; "Engenho de Mandioca", de Modesto Brocos, dentre outras 16.

No que concerne ao ensino artístico, podemos mencionar ainda algumas mudanças nada desprezíveis, como o fim da cópia de gravuras como exercício de aula, - método considerado ultrapassado -, e um maior destaque dado para o estudo da figura humana. Sabemos que embora o trabalho a partir da figura humana tenha sempre desempenhado um papel fundamental dentro da ideologia da academia, a sua prática havia sido muito irregular em períodos anteriores à República, devido principalmente às diversas carências da instituição como a falta de modelos e de instalações adequadas ${ }^{17}$. Somente após a reforma de 1890, tal prática parece ter se tornado realmente rotineira. Em seu programa da cadeira de pintura de 1892, Henrique Bernardelli reafirmava claramente esse ponto de vista:

em pintura não há maior difficuldade que a figura humana, e o artista que toma à si a responsabilidade de guiar os jovens artistas deverá continuamente observar que não se desviem desse fim: a figura humana; porque neste estudo encerrão-se todas as manifestações da pintura ${ }^{18}$.

Também a pintura de paisagem passa a possuir já na primeira década da ENBA lugar de destaque nas aulas de pintura. Se é verdade que a paisagem nunca havia sido negligenciada na AIBA - ao lado da cadeira de pintura histórica, havia nesta última uma cadeira dedicada ao estudo da pintura de paisagem, flores e animais -, é certo também que o gênero gozava de um crescente prestígio por ocasião da proclamação da República. Ele foi sensivelmente incentivado quando da criação da ENBA, provavelmente porque parecia adequar-se igualmente bem aos anseios então difundidos de criação de uma escola brasileira de pintura e à manifestação da individualidade do artista. Estudos exclusivamente dedicados à paisagem são temas que se encontram claramente explicitados nos programas de curso redigidos logo após a reforma de 1890 por

\footnotetext{
16 Arquivo do Museu Dom João VI EBA/UFRJ. Livro de Correspondências Enviadas, ENBA, 12 de março de 1892, p. 63. Livro de Correspondências Enviadas, ENBA, 17 de novembro de 1892, no, p. 95.

${ }_{17}^{17}$ Ver “A problemática da falta de modelos". In: SÁ, Ivan Coelho de. Op. cit. p.454-470

18 Arquivo do Museu Dom João VI/EBA/UFRJ. Notação: 6154. Acta da secção do Conselho Escolar em 4 de junho de 1891. p.1.
} 
Rodolpho Amoedo e Henrique Bernardelli, os dois primeiros professores de pintura da ENBA ${ }^{19}$.

Nesse sentido, é ainda mais emblemático o fato do curso especial de pintura ter sido dividido em duas cadeiras que passaram a ser chamadas simplesmente de primeira e segunda cadeiras de pintura e as quais não mais se distinguiam em função dos gêneros tradicionais, como ocorria na antiga Academia.

Esse fato não se limita a uma mera mudança de designações; o significativo aqui é que Bernardelli opta francamente em seu programa por propostas que fundiam a pintura de figura e a de paisagem. A afirmação de que "para o estudo da figura humana é necessário contemporaneamente todos os estudos, especialmente a paysagem com a figura e a figura com a paysagem" ${ }^{20}$, feita por Bernardelli, indica claramente uma orientação mais moderna, uma explícita "corrosão" da distinção e hierarquia dos gêneros, já prenunciada no período final da $\mathrm{AIBA}^{21}$.

Outras modificações podem ser sentidas em relação às Exposições Gerais (cujos regimentos só são aprovados em julho de 1893) e aos Prêmios de Viagem (cujo regulamento também é datado de 1893) ${ }^{22}$. $\mathrm{Na}$ ENBA, o Prêmio de Viagem era concedido, assim como na AIBA, mediante concurso, sendo o tempo da pensão fixado em cinco anos, no entanto várias diferenças podem ser encontradas em comentários copilados nas atas das sessões do Conselho Escolar ${ }^{23}$ e nas Instrucções para os premios de viagem aos alumnos ${ }^{24}$. Das três provas realizadas pela ENBA, a que possuía

19 Acta da secção do Conselho Escolar em 4 de junho de 1891, 1 recto; Secção do Conselho Escolar em 16 de março de 1896, 41 recto.

${ }^{20}$ Arquivo do Museu Dom João VI/EBA/UFRJ. Notação: 6154. Acta da secção do Conselho Escolar em 4 de junho de 1891, p. 1.

${ }^{21}$ Luciano Migliaccio aponta para os efeitos irônicos dessa corrosão dos gêneros na obra de Amoedo. MIGLIACCIO, Luciano. "Rodolfo Amoedo. O mestre, deveríamos acrescentar". In.: Marques, Luiz (org.). Op.cit., p.31-36.

22 Arquivo do Museu Dom João VI da Escola de Belas Artes/EBA/UFRJ. Informações retiradas do: Índice dos Decretos de criação da Escola de Belas Artes no período de 1816 a 1986. Pasta de Decretos. Pesquisa realizada pela museóloga Clelia Cerqueira Lima Celestino. s/d.

23 Acta da secção do Conselho Escolar em 13 de setembro de 1892, 6154, 13 recto. Já em 1892, visando atender de maneira mais ou menos igualitária os diversos cursos especiais, a congregação instituíra um sistema de rodízio na concessão dos prêmios: "o concurso será feito na ordem seguinte: $1^{\circ}$ anno, pintura; $2^{\circ}$ anno, esculptura; $3^{\circ}$ anno, architectura; $4^{\circ}$ anno, gravura"

${ }^{24}$ As Instruções para os Prêmios de Viagem se encontram disponibilizadas no site: www.dezenovevinte.net . 
maior peso era indubitavelmente a terceira, que exigia a realização de uma academia pintada ${ }^{25}$, um "exercício escolar usual", algo completamente diverso dos critérios vigentes na AIBA, que avaliavam os candidatos sobretudo com base na realização de uma composição acabada.

Nesse sentido, logo nos primeiros anos da ENBA é possível perceber uma ruptura com relação a orientação da AIBA: durante toda a sua primeira década o concurso de Prêmio de Viagem de pintura envolvia normalmente três provas: a realização de a) uma academia desenhada (em duas sessões de três horas), b) uma academia pintada (em 30 sessões de quatro horas) e c) um esboceto de composição (em uma sessão de oito horas $)^{26}$. O significativo aqui é que, destas três provas, a que possuía maior peso era indubitavelmente a segunda, como a sua própria duração sugeria: a primeira tinha um caráter apenas eliminatório e a terceira era "unicamente exigida para que o candidato prove se tem o dom da imaginação"27. Disso pode-se deduzir que, até o início do século XX, esperava-se sobretudo de um candidato à pensionista que ele demonstrasse competência na realização de uma academia pintada, um exercício escolar usual, algo completamente diverso dos critérios vigentes na AIBA, que avaliavam os candidatos sobretudo com base na realização de uma composição acabada.

É significativo que após a reforma de 1890, não só o tradicional prêmio destinado aos alunos da ENBA tenha tido a sua freqüência incrementada, como também, em 1894, tenha sido criado um segundo Prêmio de Viagem, anualmente concedido ao artista que mais se destacava na Exposição Geral. O Regimento das Exposições Gerais², redigido em 1893, instituía que bastando a um artista, para obtê-lo, distinguir-se significativamente no certame. A grande maioria dos laureados foram pintores, que normalmente tinham uma relação mais ou menos estreita com a ENBA, na condição de alunos livres. Uma das diferenças mais significativas entre o Prêmio de Viagem concedido aos pensionistas da ENBA e aquele dado nas Exposições Gerais. A primeira dizia respeito à duração: enquanto o tempo da estadia dos pensionistas da ENBA era de

\footnotetext{
25 Acta da $1^{\text {a }}$ seção do Conselho Escolar do anno de 1900. 6154, 91 recto. A primeira prova era possuidora de um caráter apenas eliminatório e a terceira sendo "unicamente exigida para que o candidato prove se tem o dom da imaginação".

${ }^{26}$ CAVALCANTI, Ana. Op., cit., p.47; como os pareceres dos concursos durante a década de 1890 nem sempre indicam essas três provas, é possível que tenham ocorrido alguma variações.

27 Acta da $1^{\text {a }}$ seção do Conselho Escolar do anno de 1900. 6154, 91 recto.

28 O Regimento das Exposições Gerais de 1893 está disponível no site: www.dezenovevinte.net .
} 
cinco anos, a pensão dos laureados nas Exposições Gerais durava apenas dois, embora muitos prorrogassem, por conta própria, as suas estadias ${ }^{29}$.

No que concerne as relações da Escola Nacional de Belas Artes com a arte européia, é significativo apontar a permanecia e intensificação relações entre Brasil-Itália. Tais relações, que já ocorriam no período Monárquico, são reforçadas principalmente, devido à atuação, na Escola Nacional de professores que fomentavam um forte vínculo com aquele país, muitos deles Prêmios de Viagem da AIBA. A grande maioria dos professores da nova Escola, atuantes nas áreas de pintura, desenho, escultura e arquitetura, possuíam formação italiana. Poderíamos aqui mencionar Zeferino da Costa, Rodolfo Bernardelli, Henrique Bernardelli, Pedro Weingartner, Modesto Brocos, Heitor de Cordoville, Belmiro de Almeida, dentre outros.

Ainda no que tange as relações da ENBA com a arte internacional, uma tendência ainda insuficientemente estudada, e que merece alguma atenção, foi a abertura, nos anos de 1890, da ENBA a arte dos países de língua alemã. Em meados da década, dois pensionistas - José Fiúza Guimarães e Armando de Souza Vianna -, foram designados expressamente para realizar suas temporadas de estudo em Munique.

Tal interesse pela arte "alemã"- corroborado por textos de críticos da época como Gonzaga Duque ou Carlos Américo dos Santos -, muito possivelmente foi intermediada pela significativa atuação na Itália, durante as décadas finais do século XIX, de artistas como o suíço Arnold Böcklin e os alemães Anselm Feuerbach, Hans Thoma, entre outros ${ }^{30}$.

Essas informações, que pode parecer a alguns mero detalhe, devem ser consideradas importantes para reavaliar esse período inicial da ENBA do Rio de Janeiro, principalmente no que diz respeito a sua relação com as artes italiana e alemã daquele período.

Acabamos nosso texto concluindo que a questão a ser colocada sobre a Reforma de 1890 deve ir muito além do simplesmente "falar bem" ou "falar mal" da mesma, avançando para a decisão de conhecer melhor a ENBA neste período, em toda a sua complexidade e ambigüidade. A

\footnotetext{
${ }^{29}$ Art. 31 - Este premio constará de uma pensão igual a que percebem os pensionistas da Escola Nacional de Bellas Artes, sómente pelo prazo improrogável de dous annos, e da respectiva ajuda de custo" (Regimento das Exposições Geraes de Bellas Artes. Rio de Janeiro: Companhia Industrial de Papelaria, 1885).

30 Sobre a presença dos artistas alemães na Itália, ver: I "Deutsch-Römer", Il mito dell Italia negli artisti tedeschi, 1850-1900. Milano: Mandadori Editora, 1988.
} 
pergunta que propomos ser feita ao refletismos sobre as mudanças ocorridas após a Reforma de 1890 é a seguinte: desejavam os formuladores do projeto de reforma (e os demais artistas envolvidos) uma ruptura radical com sistema de ensino da AIBA? E será que de fato não ocorreram mudanças significativas no sistema de ensino da ENBA?

Acreditamos que a proposta dos professores da Escola era unir modernidade e tradição. Para se fazer uma escola moderna de arte, em sintonia com as inovações do seu tempo, não era necessário, na concepção dos nossos artistas, romper com toda arte e todo pensamento artístico formulado anteriormente. Os artistas envolvidos com a implementação da Reforma na Escola optaram por manter traços fundamentais que caracterizavam já a Academia Imperial, remodelam-do-os por novas concepções que circulavam no meio artístico internacional. É nesse contexto, de uma modernidade que não é pensada como ruptura com o passado, que podemos compreender os anos inciais da Escola Nacional de Belas Artes. 